\title{
Scleral buckling-a brief historical overview and current indications
}

\author{
Aijing Wang ${ }^{1} \cdot$ Martin P. Snead ${ }^{1}$
}

Received: 27 August 2019 /Revised: 17 November 2019 / Accepted: 3 December 2019 / Published online: 11 December 2019

(C) The Author(s) 2019

\begin{abstract}
The key to successful management of rhegmatogenous retinal detachment (RRD) is to find and seal all of the retinal breaks, and the two main surgical techniques used to achieve this are scleral bucking (SB) or pars plana vitrectomy (PPV). Techniques for SB have remained mostly unchanged for the last 60 years, whilst PPV techniques and instruments have developed substantially over that time and have greatly contributed to increased success rate for types and configurations of retinal detachments unsuitable or difficult to manage with buckling alone. However, there is a growing dependency to rely on PPV as the sole and only approach for repair of all types of retinal detachment, such that some centres are no longer offering training in scleral buckling. There are also many studies comparing SB with PPV, but many of these lack information on the type, technique or rationale for deployment of the buckle. Many studies deploy the same scleral buckle technique without customising it to the type, position or number of tears being treated. Scleral buckling is not a one-size-fits-all technique. It requires careful patient selection and careful buckle selection and orientation tailored to the tear(s) to ensure success. When used appropriately, it is a simple and highly effective technique, particularly for retinal dialyses, round retinal hole detachments and selected cases of retinal detachment associated with horseshoe retinal tears. There is no doubt that for some more complex cases, such as multiple large breaks, giant retinal tears, bullous detachments and cases complicated by proliferative retinopathy, PPV offers a safer and more effective management. However, SB remains an important and relevant surgical technique, and for the right cases, the results can be superior to PPV with reduced comorbidity.
\end{abstract}

Keywords Rhegmatogenous retinal detachment $\cdot$ Scleral buckling $\cdot$ Par plana vitrectomy

\section{Introduction}

Scleral buckling (SB) has been used either as the primary or as an adjunctive treatment for rhegmatogenous retinal detachment (RRD) repair for over 60 years. However, certain types or configurations of retinal detachment are difficult or impossible to manage with scleral buckling alone, and the advent and development of pars plana vitrectomy (PPV) for retinal detachment repair has greatly enhanced the outcomes in such cases. Internal approaches are now so widespread for all types of retinal detachment repair that some surgeons are no longer being exposed to training in scleral buckling. This paper reviews the literature and highlights the important role that buckling continues to offer for successful retinal detachment repair and describes some of the key surgical elements.

Martin P. Snead

mps34@cam.ac.uk

1 Vitreoretinal Service, Cambridge University NHS Foundation Trust, Hills Road, Cambridge CB2 0QQ, UK

\section{A brief history of scleral buckling}

Any attempt to summarise the history of retinal detachment repair must begin with Jules Gonin's pioneering observation that accurate localisation and sealing of the retinal break(s) was the key to successful re-attachment. A common belief in his era was that retinal breaks were either not present or were otherwise secondary to retinal detachment [1-3]. Since then, many different techniques have been developed to treat retinal breaks, but this article focuses particularly on the roles of scleral buckling.

Scleral buckling surgical techniques originally evolved from scleral resection [4] which was initially developed to reduce the size of the eyeball [5] or as an attempt to strengthen the sclera and prevent stretching. It was subsequently realised that as a result, this actually brought the retinal pigment epithelium and neurosensory retina together, assisting retinal reattachment [6]. Full thickness scleral resection was then refined to lamellar scleral resection in 1949 by Shapland [7] to decrease the ocular complications from scleromalacia-a common association with rhegmatogenous retinal 
detachment. The area of the resection often resulted in a buckling effect, and attempts were made to localise the resection site over the break, in order to aid retinal re-attachment.

However, even lamellar resection carried a high risk of comorbidity and attempts to achieve the same buckling effect without risking tissue resection were therefore developed. These techniques included Weve's 'reefing' procedures [8], scleral out-folding procedures [9-11], scleral in-folding procedures [12-17] and scleral shortening by shrinkage with diathermy [18]. With all of these techniques, the main objective was the 'buckling' effect that was produced, which became a key factor in successful retinal re-attachment.

Whilst the scleral shortening techniques were being elaborated, in 1949, Ernst Custodis developed an explant specifically to produce a buckling effect for retinal detachment repair whilst circumventing the risks associated with scleral shortening and resection (Fig. 1) [19]. Custodis introduced a polyviol explant to buckle the sclera, breaks were treated with diathermy and a non-drainage procedure was used. He reported his technique with a consecutives series of 515 patients with an $83.3 \%$ rate of success - a figure that compares favourably with many series being published 50 years later [19].

In the USA, scleral buckling was also being developed by Charles Schepens, who deployed a polyethylene encircling tube and drained subretinal fluid along with diathermy [20-24]. Schepens also contributed hugely by developing and popularising the use of the binocular indirect ophthalmoscope which greatly enhanced the wide-field fundus visualisation vital for break identification and retinal detachment repair $[25,26]$. In New York, Harvey Lincoff, perhaps above all others, made many important and varied contributions to the development of scleral buckling. He introduced silicone sponges as explants; developed new needles for scleral sutures; published extensively on the advantages of cryotherapy over diathermy, the importance of finding the retinal break (now universally known as 'Lincoff's rules' [27]) and the importance of buckle orientation for different configurations and types of retinal break; and highlighted the lower comorbidity of non-drainage of subretinal fluid [28-35]. The

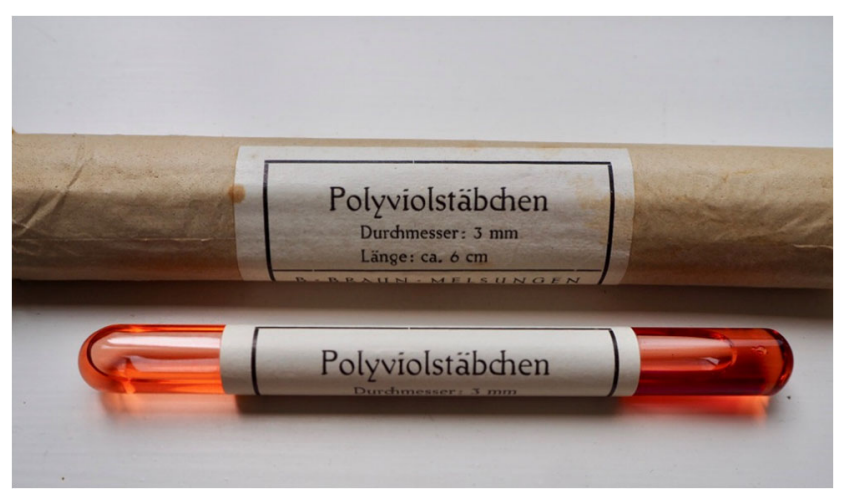

Fig. 1 Custodis polyviol explant from the 1940s techniques he developed 50 years ago have withstood the test of time and remain as relevant in retinal detachment repair today.

\section{Changes in retinal detachment surgery}

Scleral buckling became an established technique for retinal detachment repair, with long-term studies reporting a 95\% final success rate at 20-year follow-up [36], only 13-23\% re-operation rate [36-38] and a median visual acuity at $6 / 12$ at long-term follow-up [36, 38]. Other large studies have shown with careful case selection a $99 \%$ single operation success, a figure never achieved in any vitrectomy series [39]. However, since the development of pars plana vitrectomy by Machemer [40, 41], there has been a great shift towards PPV over SB in the surgical management of RRD [42-51], and whilst both have a role to play, there have been major debates [52] about which type of surgery is better suited for which type of patients. Unfortunately, there is a paucity of robust evidence to definitively confirm either being superior to the other, or which is indicated in which patients, largely because of failure to sub-classify different retinal break types in the comparison analysis (Table 1) [53].

One of the largest trials comparing SB and PPV was conducted by the SPR (scleral buckling versus primary vitrectomy in rhegmatogenous retinal detachment) study group. It concluded that SB was superior for phakic patients, as improvement in best corrected visual acuity (BCVA) was significantly better $(p=0.0005)$ in the SB group compared to the PPV group, but PPV was better for aphakic/pseudophakic patients in terms of anatomical success [54]. There was no significant difference in improvement of BCVA between the $\mathrm{SB}$ and PPV groups in aphakic/pseudophakic patients $(p=$ 0.1033 ), which was the primary outcome of the study. The study argued that PPV was better for aphakic/pseudophakic patients due to better primary anatomical success rates (SB $53.4 \%$, PPV $72 \%, p=0.0020$ ) and fewer retina-affecting operations in the PPV group. However, the final anatomical success rates were not significantly different. Therefore, the evidence to support PPV for aphakic/pseudophakic patients was not as convincing as the evidence to support SB for phakic patients. It is also important to note that the primary anatomical success rates in the SPR trial were much lower than those in other trials $[55,56]$. The study did not directly analyse PPV alone in comparison with PPV combined with SB, but found that anatomical results were superior in aphakic/pseudophakic patients that incorporated an additional buckle. With combined PPV and buckle, there was an $11.4 \%$ failure rate, whereas with PPV alone, $40.9 \%$ of patients re-detached. This was a very significant difference and other studies have also shown higher rates of success in PPV combined with SB over PPV alone, lending support to the role of scleral buckling as an 
Table 1 Cambridge guide to characteristic retinal break types in rhegmatogenous retinal detachment [RRD]

\begin{tabular}{lllll}
\hline Break type & Sex & PHM & Refractive error & Fellow eye pathology \\
\hline Horseshoe tear & M=F & OFF & Myopic & $15 \%$ \\
Round hole & F $>$ M & ON & Myopic & $50 \%$ \\
Dialysis & M $>$ F & ON & Hypermetropic & $15 \%$ \\
Giant retinal tear & M=F & OFF & Myopic & Up to $80 \%$ \\
Macular hole & $\mathrm{M}=\mathrm{F}$ & OFF & Highly myopic & Rare \\
Retinoschisis RRD & $\mathrm{M}$ & ON & Hyperopic & $80 \%$ \\
\hline
\end{tabular}

$P H M=$ posterior hyaloid membrane adjunct to vitrectomy in certain circumstances, in addition to those that can be managed successfully by buckling alone [57]. Unfortunately, no details were reported in the comparison study on SB techniques, merely that radial sponges or encircling elements were used.

Many other studies, similar to the SPR study group, support the use of PPV for pseudophakic eyes [54, 55, 58], whereas other studies have shown no difference between SB versus PPV in pseudophakic eyes [59-61]. There is little evidence or logic to suggest one size or technique fits all scenarios. The surgical objective must be to identify and close all retinal breaks with a single (first) procedure. Patients may therefore require either PPV or SB or a combination of the two to achieve this objective and surgeons should not be restricted in their approach to one or the other.

The general consensus is that an 'uncomplicated RRD' can be managed with scleral buckling alone and tends to give higher rates of success [54, 59, 62-66]. However, the development and increasing use of PPV for a wide variety of vitreoretinal disorders has perhaps led to an incremental decline in the training and therefore deployment of SB, even for cases of 'simple' RRD [67].

The use of SB combined with PPV for treating inferior tears [68] versus PPV alone also remains open to debate. Some groups argue that PPV with tamponade alone is sufficient as a primary approach [69-71], whilst others make the case that scleral buckles can provide an important adjunct to the internal tamponade to achieve successful closure of all breaks [72, 73]. Many studies have shown that eyes with inferior breaks generally have worse prognosis than eyes with superior breaks [46, 68, 74]. Studies reporting PPV alone for RRD with inferior tears give primary success of around $81 \%$ with no significant improvement when an additional buckle was used $[69,70]$. In contrast, other studies in which a combined approach was deployed reported a single operation success rate of $95 \%$ [72].

A weakness common to many of the studies comparing SB and PPV for RRD is a paucity of data on the type, technique or rationale for deployment of the buckle, in contrast to the more uniform approach of three-port PPV. Many studies deploy the same scleral buckle technique without customising it to the type, position or number of tears being treated $[44,55,56]$. The importance of pinpoint accuracy in buckle localisation highlighted by Lincoff, Scott and others [27, 65, 75-77] remains the key factor in successful buckle deployment. It is perhaps not surprising that in comparative studies of SB versus PPV, failures in the former were all caused by malposition of the buckle $[44,55]$. When buckles are not appropriately selected or localised to achieve break closure according to the exact size and position of the retinal tear, breaks will not close and re-attachment will not be achieved. Most studies that analyse SB versus PPV report the use of circumferential buckles or $360^{\circ}$ encircling buckle. However, 'fishmouthing' is a risk if horseshoe tears are managed in this way [78], unless combined with an internal tamponade. Circumferential buckles are better suited and highly effective for the repair of dialyses and round retinal holes in which the vitreous and posterior hyaloid membrane are characteristically attached, and radial sponges are better suited for horseshoe tears [75].

In another study, the technique of SB was the universal use of a silicone tyre and band irrespective of size, position, number and position of tears [56]. As patient selection is a key component to the success of scleral buckling surgery, results from these studies need to be interpreted with caution. When scleral buckling is carefully selected according to operative findings, complete single operation success can be achieved in as high as $93.6 \%$ [60] and 99\% [39].

The United Kingdom National Ophthalmology Database Study showed that the re-operation rate was lower for patients who underwent SB (12.3\%) versus PPV (13.0\%) or PPV+SB (14.5\%), although the figures did not reach statistical significance. Also, the rates of visual success were higher for SB (71.6\%), although this was not significantly higher than PPV (69.7\%) or PPB+SB (65.6\%) [79]. This set of results is echoed in the Medicare data from the USA, where the rates for second operation were higher for PPV (21.2\%) when compared with SB (19.2\%) [80]. The Medicare data also reported that patients undergoing PPV were two times more likely to experience adverse outcomes compared to the scleral buckling group (OR 2.019; 95\% CI 1.412, 2.889). Another smaller study also shows patients treated with $\mathrm{SB}$ required lower number of re-operations compared to PPV [81]. Interestingly, a 
retrospective study of 1530 eyes conducted in Singapore showed that scleral buckling had the highest primary anatomical success ( 88.8 vs $78.6 \%$ ) and the best functional outcome compared to PPV ( 86.1 vs $72.5 \%$ ), and the SB group also had less complications [82]. This study unfortunately did not specify the type of tears that were being treated, but it is likely that round hole retinal detachments which respond well to buckling were a significant proportion of that population [83]. If so, this would echo the UK study of the largest reported series of RRD secondary to atrophic round retinal holes in which $99 \%$ single op success was achieved [39] emphasising the importance of careful case selection and break type being tailored to the surgical approach.

In summary, rhegmatogenous retinal detachment is a highly heterogeneous disease and its management equally so. Scleral buckling retains a very important role in the management of certain types of RRD, either as a primary approach with very high single operation success rate and low comorbidity, or as an adjunct to enhance a combined internal approach with PPV. The definition of anatomical and visual success varies between studies, but the primary goal for surgeons must be an approach tailored to the individual patient's needs that will result in permanent re-attachment with a single procedure whilst minimising comorbidity.

\section{How does scleral buckling work?}

\section{Primary scleral buckling}

Whether an internal, external or combined approach is chosen, the principal objective is to close all retinal breaks and maintain closure by preventing any further recruitment of subretinal fluid for long enough for a retinopexy adhesion to mature to full strength.

In primary $\mathrm{RRD}$, once this has been achieved, the tamponade (either internal or external) serves no further purpose in maintaining retinal re-attachment as evidenced by the temporary nature of gas tamponades. There is, however, usually no need to remove a scleral buckle once primary repair has been achieved, but in the same way that a gas tamponade is temporary, it is quite safe to do so should the need arise.

\section{Secondary scleral buckling}

Scleral buckling can also play an important adjunctive role to PPV in the management of more complex RRD associated with multiple or large retinal breaks, proliferative vitreoretinopathy (PVR), schisis and patients in whom postoperative posturing with PPV alone may be problematic [84].

\section{Surgical technique}

The specific surgical techniques for scleral buckling are many and varied, but there are three main fundamental principles which are key to primary success:

1. A thorough preoperative and intraoperative examination is essential to identify and localise all retinal breaks [85] and the pioneering 'rules' introduced by Harvey Lincoff and Dick Gieser [27] remain as an important foundation on which to base the examination.

2. Accurate retinopexy.

3. Correct buckle selection and pinpoint accurate localisation to occlude the break and maintain apposition of RPE and neurosensory retina whilst the retinopexy matures to full strength.

Most failures of scleral buckling arise from either missed primary breaks or inaccurate localisation of the buckle and thereby failure of break closure.
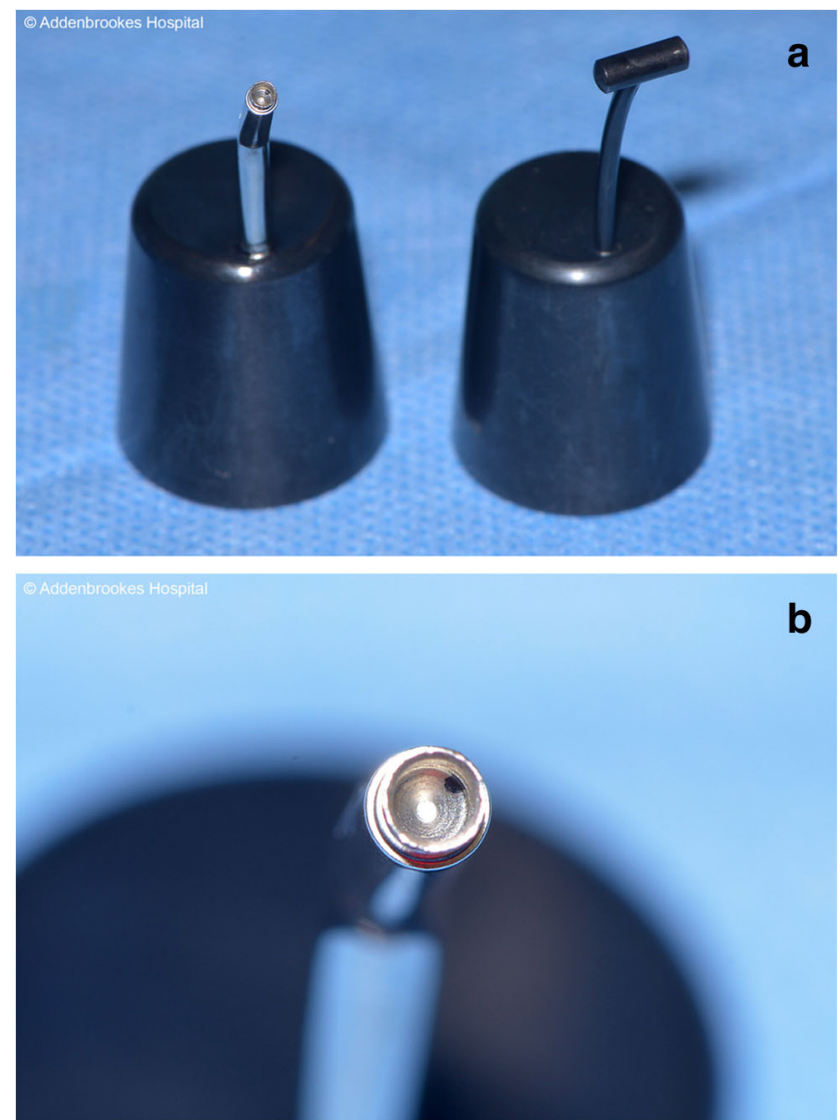

Fig. 2 a Left: The Gass scleral marker aids accurate localisation of the corresponding position of breaks on the external scleral surface. Right: Use of a scleral depressor greatly enhances peripheral retain examination with indirect ophthalmoscopy — small peripheral breaks can be opened or thrown into relief to assist identification. b The Gass scleral marker 


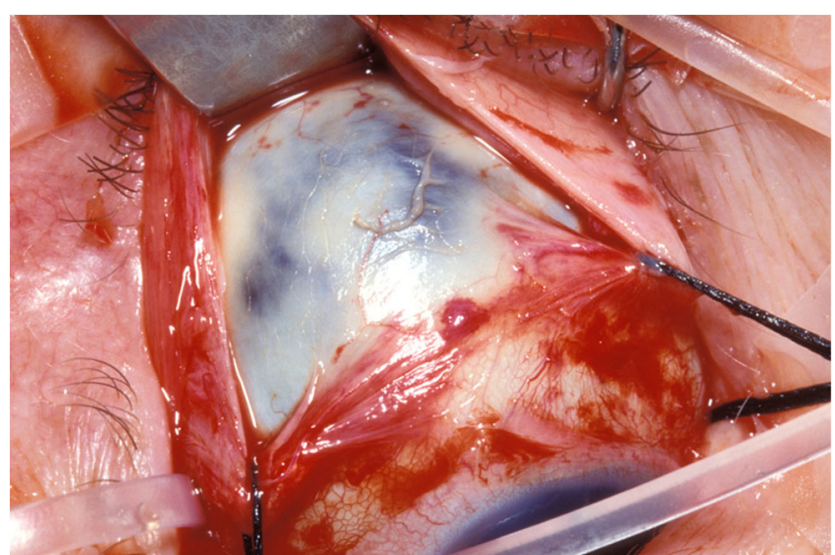

Fig. 3 Scleromalacia identified at surgery. Such operative findings would probably dictate a switch to an internal approach

\section{Examination of the sclera and retina}

A full peritomy should be performed to ensure all parts of the sclera and retina (both attached and detached) can be fully examined with scleral depression (Fig. 2a, b). Opening the conjunctiva $2-3 \mathrm{~mm}$ posterior to the limbus provides good scleral access without any disturbance to the Tenon's capsule/conjunctival complex which reduces scarring as well as avoiding disruption to the limbal stem cell array.

The four rectus muscles are isolated on bridle sutures with great care taken at this step to avoid splitting a muscle, slinging an oblique or stripping the muscle capsule all of which increase the risks of restrictive diplopia postsurgery. The peripheral retina can then be meticulously examined to identify all breaks and the sclera for any associated scleromalacia which might compromise or preclude safe buckle suture placement (Fig. 3).

Following examination, each retinal break must be localised and marked (see Figs. 2b, 4 and 5). For small tears, one indentation may be sufficient to help decide the size of

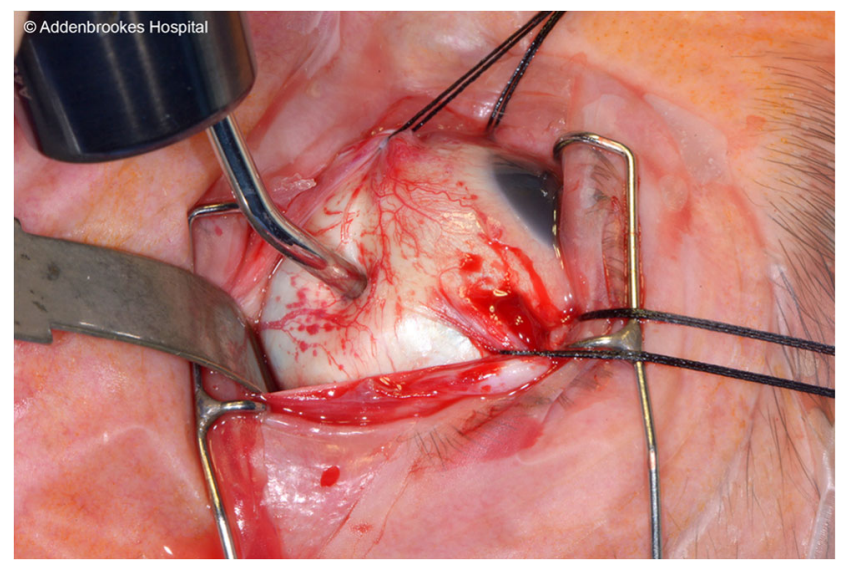

Fig. 4 Gass scleral marker being used to localise the exact position of retinal break on corresponding scleral surface. Pinpoint accuracy of break localisation is key to successful break closure

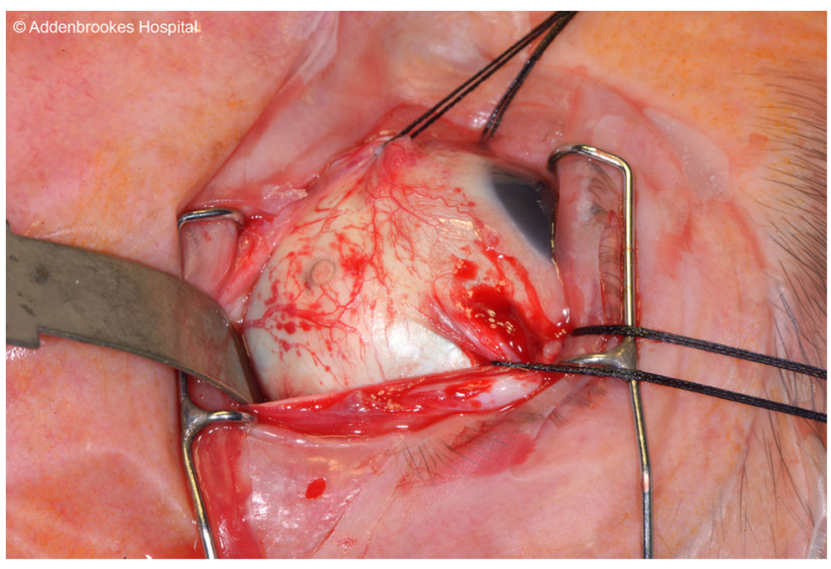

Fig. 5 The temporary mark made by the Gass scleral marker dehydrating the sclera will fade in a few minutes; therefore, it is helpful to put a superficial suture through the mark as a more permanent measure (see Fig. 8)

buckling material. For larger tears, three indentation marks may be needed to mark the anterior horns and the posterior limit.

\section{Sealing the break}

After localising the breaks, retinopexy is applied accurately to each break, ensuring no gaps are left with large tears and no area retreated which might compromise the RPE/Muller cell adhesion. If the detachment is bullous or too elevated to deploy retinopexy accurately to both RPE and neurosensory retina, then the subretinal fluid may be released with an air injection to restore the volume and IOP in the D-ACE surgical sequence [86]. Accurate localisation and retinopexy is a most important element of the operation. If any tears are missed, the primary surgery will fail. Cryotherapy is most commonly used and often better at highlighting small tears in the periphery

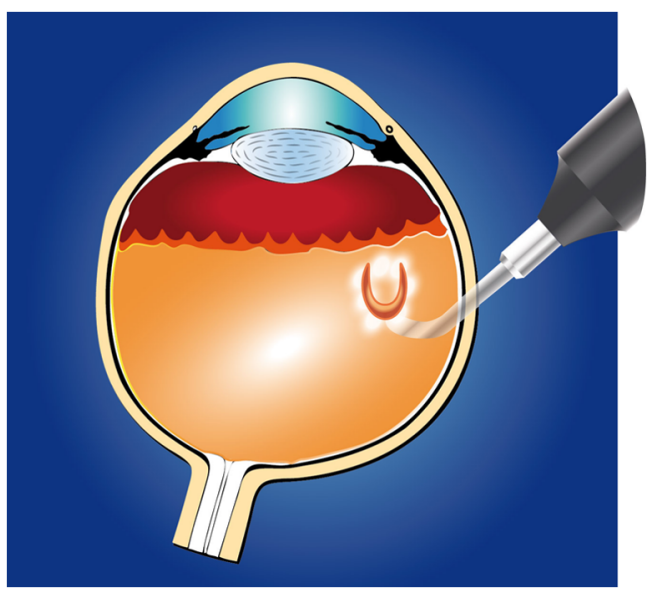

Fig. 6 Cryoretinopexy being applied to a horseshoe tear. For most tears, a single application is all that is required to completely surround the break. For very large tears, several applications may be required to cover the entire break, but there should be no gaps between applications and no overlap of treatment 


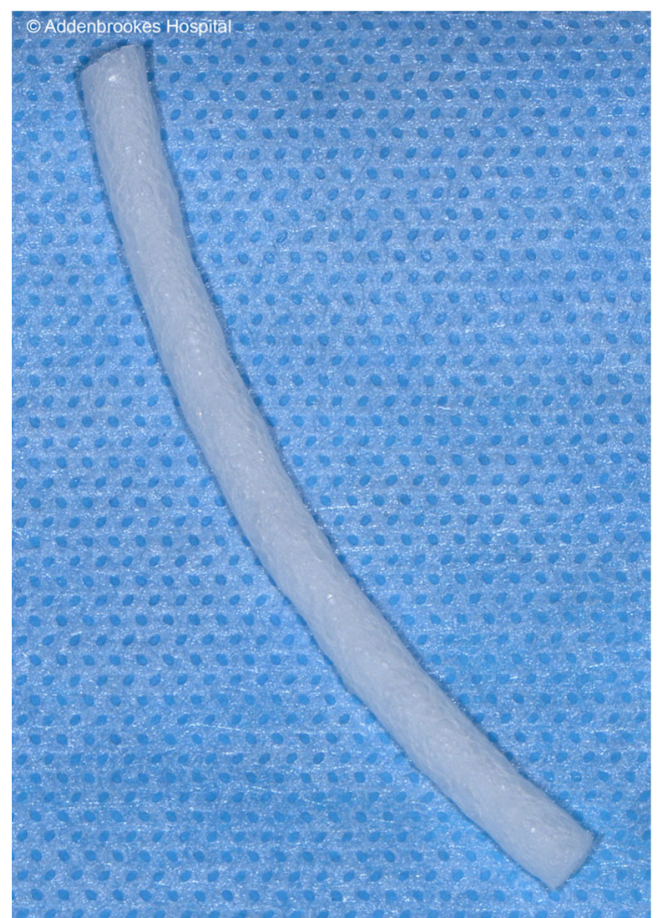

Fig. 7 A scleral sponge provides excellent break closure when applied radially for horseshoe tears and is also highly effective for closure of dialyses when applied circumferentially, reducing the risk of motility and pressure issues that may accompany more extensive solid silicone explants

compared to laser and has better outcomes than laser [87] in the context of scleral buckling for retinal detachment (Fig. 6).

\section{Choice of buckle}

There are three main different categories of buckle deployment: radial buckle, segmental circumferential or encircling. The types, number and magnitude of the retinal tears will influence the selection.

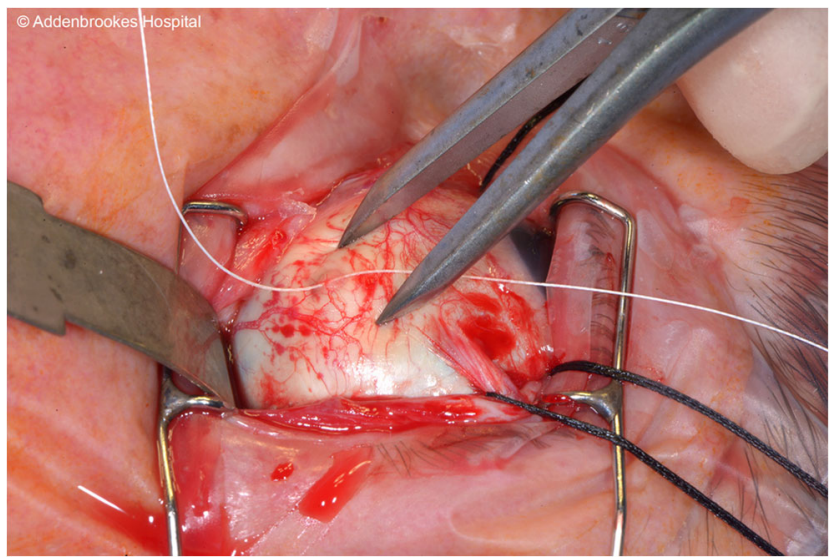

Fig. 8 The temporary scleral mark has been marked with a temporary stitch. The callipers are marking the width of the mattress suture, which is determined by the diameter of the buckling material, which in turn is determined by the size of the retinal tear

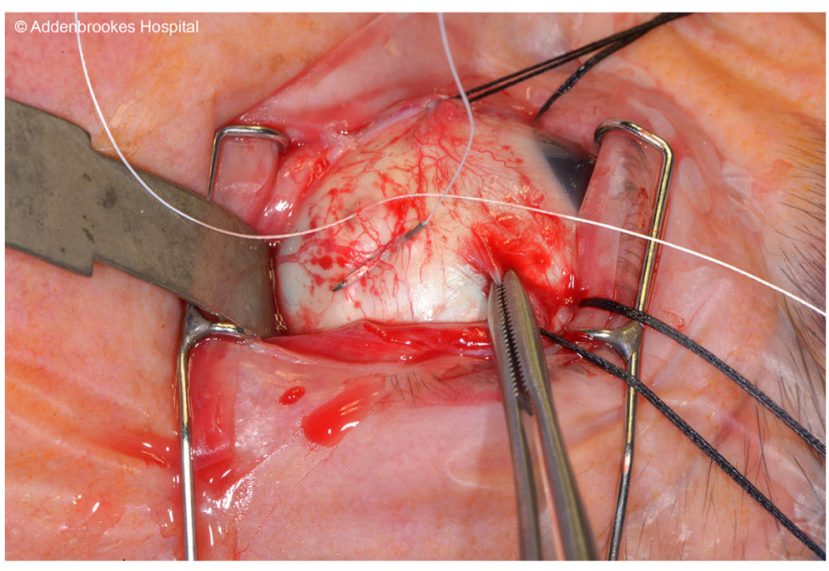

Fig. 9 The start of the mattress suture using a spatulate needle with two cutting edges attached to a 5-0 non-absorbable suture

In general, a single horseshoe tear is most effectively closed with a radial sponge (Fig. 7). The figures provided show an illustrative guide for applying a radial sponge, from EUA to retinopexy, localisation and then buckle placement (Figs. 3, 4, $5,6,7,8,9,10,11$ and 12). Retinal dialyses and atrophic retinal hole are managed very effectively with a circumferential explant. Multiple and/or very large tears are usually more safely and effectively managed with an internal approach.

After the correct type of buckle is selected, accurate suture placement (Fig. 8) is the next key step as this will determine not only the localisation of the buckle over the break but also importantly the buckle height. Suturing the buckle to the sclera is a skill that requires training and practice. The sutures should be deep enough to be secure but not so deep to lead to premature loss of subretinal fluid which could compromise intraocular pressure or result in choroidal haemorrhage. The scleral passage should be uniform in depth and as long as feasible (Figs. 9, 10 and 11b). A spatulate needle with two cutting edges attached to a 5-0 non-absorbable suture is generally the material of choice.

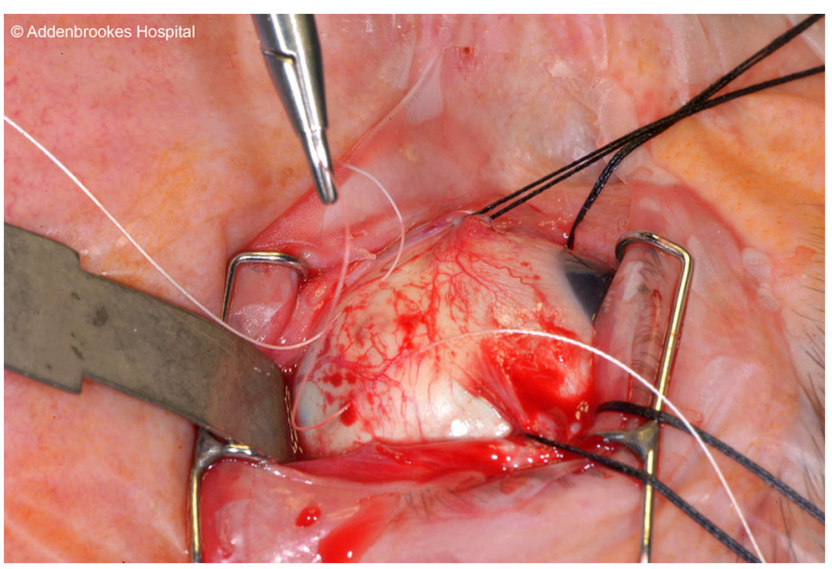

Fig. 10 The mattress suture. Applying the suture with both passes anterior to posterior reduces the risk of inadvertent perforation (see Fig. 11a and $\mathrm{b}$ for the technique for completion of mattress suture) 
Fig. 11 a Applying the two suture passes to construct the mattress suture. Top - access for the second pass posteriorly may be compromised with large globes and risks inadvertent perforation. Bottom and $\mathbf{b}$ illustrate a safer approach. b Completion of the mattress suture. The width of the suture is $7 \mathrm{~mm}$, whilst the sponge size was $4 \mathrm{~mm}$. Adequate buckle height is achieved with this and the tear is effectively draped over the buckle

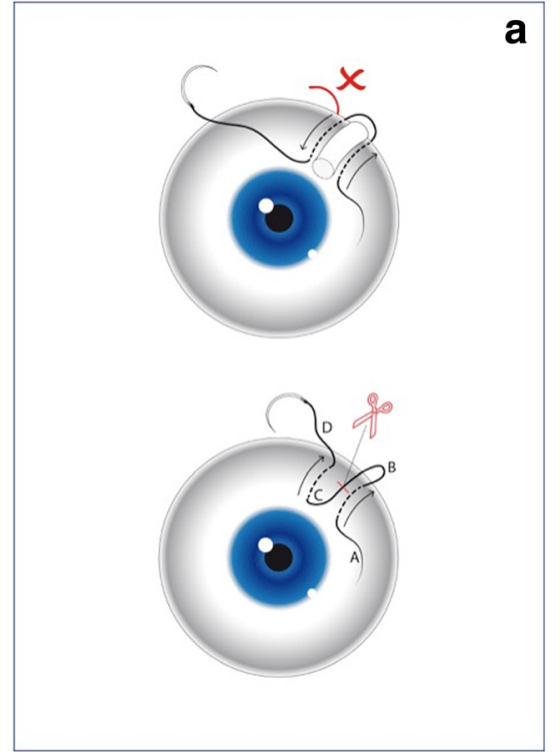

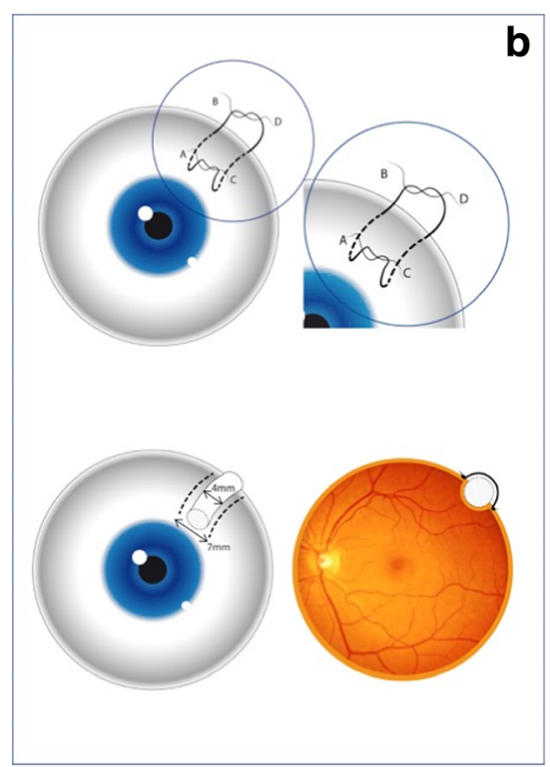

The mattress suture width will be determined by the size of the buckling material, which is in turn determined by the size of the tear. The diameter of the buckle must be big enough to cover both apices of the horseshoe tear, and the width of the suture (the extra-scleral portion) must be wider than the diameter of the explant in order to achieve an adequate buckling effect to drape and close the break effectively. No amount of suture tightening will achieve an adequate buckle height if the sutures are too close to the explant- the sutures will simply cut out of their scleral passage. Too far apart and the explant may shift position allowing one or another horn of a horseshoe tear to leak.

The length of the buckle must close both the posterior edge of the break and the limit of separation of the posterior hyaloid membrane at the anterior horns of a horseshoe tear. Circumferential buckles are placed in a similar way, with

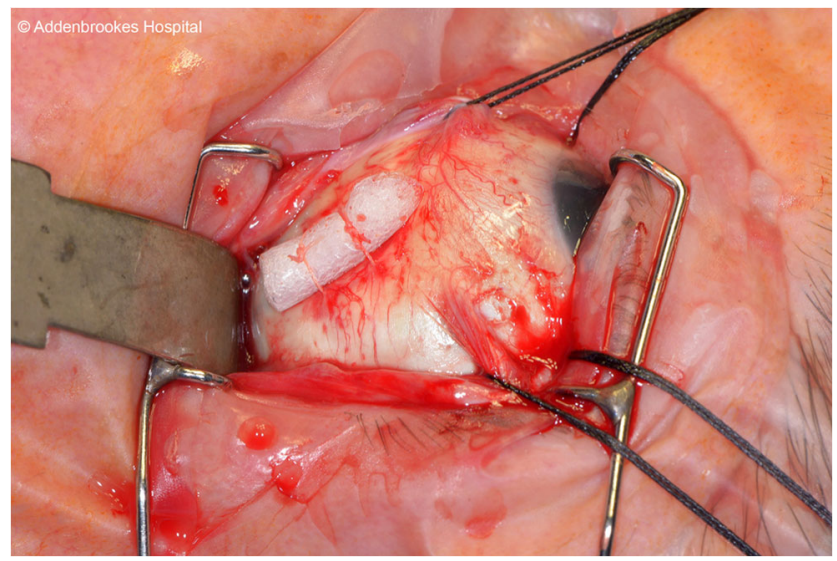

Fig. 12 The position of the buckle is checked with indirect ophthalmoscopy to ensure accurate and adequate break closure before finally trimming the buckle ends flush with the sclera sutures on either side of rectus muscles when required for extensive circumferential breaks.

When tying the surgical knot, the first throws determine the tension and hence the buckle heightgenerally a triple throw being sufficient for a for 3, 4 or $5 \mathrm{~mm}$ diameter sponge (Fig. 11b). A quadruple throw may be required for $7.5 \mathrm{~mm}$ sponges, although these are rarely used now with internal approaches being preferred for such very large single horseshoe tears. The knot must be balanced, so that equal tension is produced on both sides of the knot when complete (Fig. 12). Whilst the knots are tied, it is important to monitor the intraocular pressure. The risk of increased intraocular pressure is increased with the size of the buckling material being used.

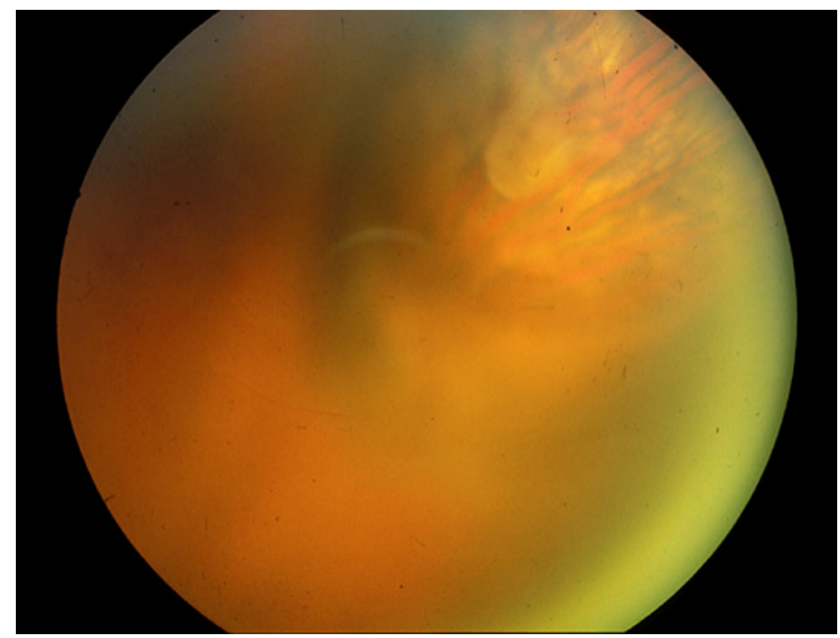

Fig. 13 This shows a successfully treated horseshoe tear with a radially orientated buckle 


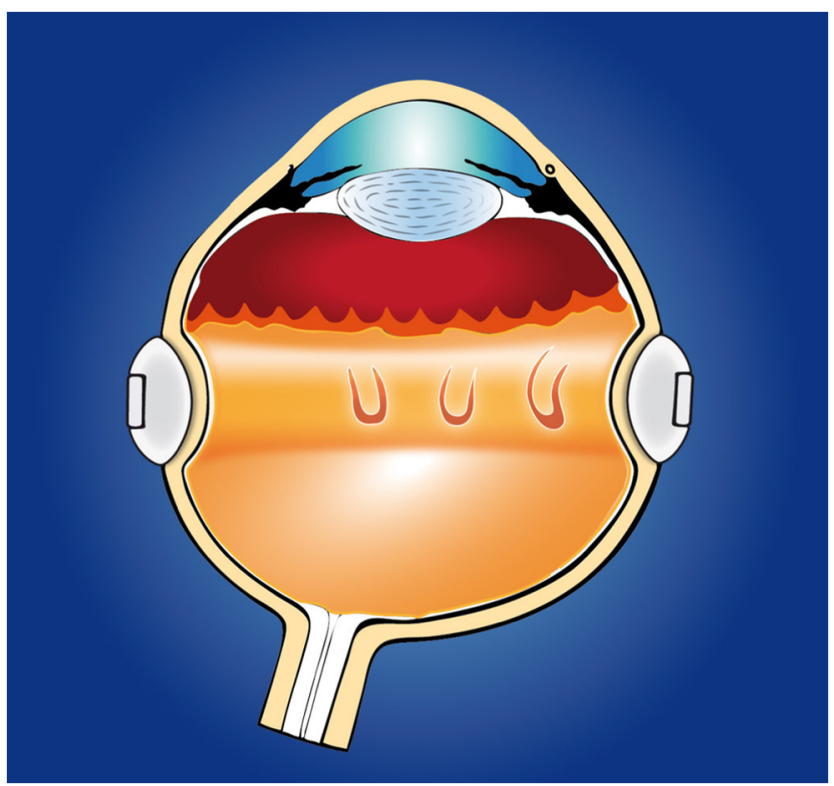

Fig. 14 Horseshoe tears are usually treated with a single radial sponge. In the case of very small and multiple horseshoe tears, a circumferential sponge may be used and 'fish-mouthing' will not occur

\section{Scleral buckling for different types of detachments}

\section{Retinal detachment secondary to horseshoe tears}

Much of the literature refers to uncomplicated retinal tears being most suitable for scleral buckling. The simplest case of a retinal detachment could possibly be defined as a single horseshoe tear with detachment extending up to two quadrants. By following the main principles of scleral buckling, the tear is first localised and treated with retinopexy and then a buckle is applied. Subretinal fluid may or may not need to be released either to restore the intraocular pressure to a normal level or to ensure the break is draped appropriately and

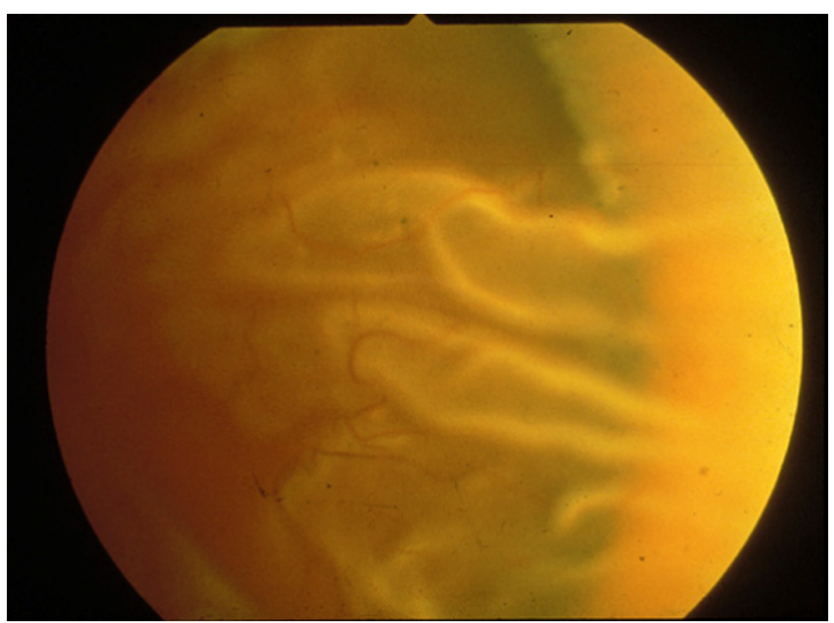

Fig. 15 Fish-mouthing phenomenon occurring when a circumferential buckle was deployed unsuccessfully accurately over the buckle. If the tear is small and undistorted, a radial buckle is likely to be all that is required (Fig. 13). Multiple tears, tears with rolled edges and big tears are generally not suitable for buckling and are safer managed internally. Circumferential buckles should generally be avoided for horseshoe tears unless the tears are very small (Fig. 14) as they can cause 'fish-mouthing' over the buckle [78, 88] resulting in inadequate break closure (Fig. 15). Fishmouthing occurs due to coronal rather than sagittal scleral shorting. In cases where there is associated scleromalacia at the site of the proposed buckle, the explant may be supported by an encircling band or the case may be managed with PPV.

\section{Detachment secondary to retinal dialysis}

Retinal detachment secondary to retinal dialysis presents as a retraction/disinsertion of the retina from the ora serrata. The dialyses often extend over several clock hours and frequently involve over $90^{\circ}$ of retina, leading to some being erroneously classified as giant retinal tears (GRT). In contrast to GRTs, the vitreous and posterior hyaloid membrane (PHM) are typically attached in cases of retinal dialysis (Table 1). Traditionally often considered 'simple' cases for the vitreoretinal trainee, accurate localisation of the buckle can be more difficult to judge than might be anticipated due to parallax leading to an apparently greater retraction of the break than is actually the case. This can lead the unwary to position the buckle too posteriorly than is required. It can be helpful therefore to localise and mark the apices of the tear (which will be at the ora serrata), and then localise the mid-point as the posterior limit and most can be successfully closed with nothing larger than a 3 -mm circumferential sponge. It is also important to ensure the other eye is inspected as there is a $15 \%$ incidence of bilateral involvement in non-traumatic dialysis [89].

In a retrospective study done by Kennedy et al., the primary anatomical success rate was $98 \%$ surgically [90], and $97 \%$ of these patients had scleral buckling procedures. The other 3\% of patients had vitrectomy and gas tamponade. Other studies have also shown high success rates of re-attachment from surgical intervention, varying between 96 and 100\%, though the actual surgical technique used is not always specified [91-93]. In a more recent study, $87 \%$ anatomical success rate was achieved in patients after one procedure, and the success rate rose to $97 \%$ after two procedures. All of the patients in this study had retinal detachments caused by dialysis and were all treated with circumferential buckles [94].

\section{Retinal detachment secondary to atrophic round holes}

Scleral buckling is the approach of choice for retinal detachment secondary to atrophic round retinal holes. Not only does it offer a far higher primary success rate than PPV (which may 


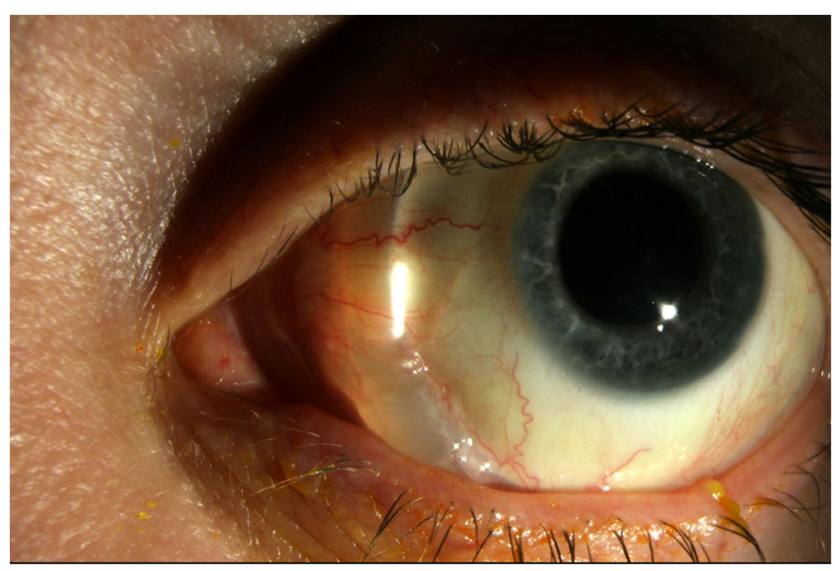

Fig. 16 An encircling band not applied on a great circle of the globe is unlikely to be stable and may migrate anteriorly as illustrated here

be challenging as the vitreous and PHM are typically attached), an external approach reduces the risk of secondary nuclear sclerotic cataract. In the largest ever study conducted of retinal detachment secondary to round holes [39], successful re-attachment was achieved in $99 \%$ with a single procedure. Multiple round holes were repaired with encircling or circumferential explants, and solitary round holes were repaired with radial buckles. Other papers have also reported similar re-attachment rates after scleral buckling for round holes. In a study conducted by Tillery and Lucier in 1978, the re-attachment rate was 98\% [64] and in another study by Greven et al., the initial re-attachment rate was $100 \%$ with scleral buckling and cryopexy [95].

In cases with multiple retinal holes in all four quadrants, an encircling band localised over each hole is often the most straightforward approach. The band can be secured with sutures in each quadrant and joined by a Watzke sleeve using a Scott threader allowing correct adjustment of the tension of the band. Where breaks are anterior to the equator of the globe, an important point is to ensure the encirclement lies along a 'great circle' of the globe for stability and to avoid postoperative slippage (Fig. 16).

\section{Superior bullous detachments}

Conventional scleral buckling may be suitable in selected superior bullous detachments if the tear can be accurately localised, either because the break itself lies in a non-bullous area, or more usually by deploying the D-ACE surgical sequence [86], but usually these cases are more safely managed by an internal approach with vitrectomy and gas tamponade.

\section{Scleral buckles as an adjunct to vitrectomy}

For inferior breaks in particular, when a scleral buckle is used in addition to PPV, the success rates are higher than PPV alone [69-73]. As with all types of tears, in order to achieve successful re-attachment, break localisation is just as important with PPV as it is with scleral buckling. In the comparative studies comparing PPV alone and PPV combined with SB, an encircling band at the equator is almost always used for buckling $[69,70]$. The choice of an encircling buckle arbitrarily deployed at the equator would not be expected to provide any addition benefit unless the tears are also coincidentally located at the equator and so comparative studies do not show higher rates of success when an additional buckle is deployed in this way. The same rules of buckling apply (localisation of break and selecting the correct size and localisation of buckle) even when a buckle is used as an adjunct to vitrectomy.

Another effective use of scleral buckle can be as an adjunct with internal approaches for cases of RRD complicated by PVR. Management of complex PVR is outside the scope of this article, but in such cases, complete dissection and removal of the vitreous and membranes may not always be possible, and circumferential shortening often persists. In such cases, a scleral buckle can be deployed to facilitate apposition of the RPE to neurosensory retina [84, 96-100].

\section{Complications of scleral buckling}

Although some have argued against scleral buckling due to side effects such as diplopia, strabismus and refractive changes, these are not common complications. Reports of diplopia postsurgery are as low as $2.5 \%$ [101] and infection is rare (0.8\% [36] to $2 \%$ [102]) with careful 'no touch' handling of the buckle during surgery and meticulous and accurate closure of the conjunctival/Tenon's complex.

\section{Conclusion}

There is no doubt that PPV has revolutionised and enhanced the successful management of retinal detachment particularly for complex cases, which previously responded poorly to external approaches, particular examples of which include multiple large breaks, giant retinal tears, bullous detachments and cases complicated by PVR. There is danger, however, that increasing dependency on PPV as the sole and only approach for repair of all types of retinal detachment will result in vitreoretinal surgeons and trainees losing (or never acquiring) the skills required for accurate scleral buckling. It remains a simple and highly effective technique for retinal detachment repair, particularly retinal dialyses, round retinal hole detachments and selected cases of retinal detachment associated with horseshoe retinal tears and as an adjunct to vitrectomy. With careful case selection and correct technique, the results can be superior to PPV with reduced comorbidity. Likewise, PPV offers superior results for cases unsuitable for an external approach and careful case selection is key. 
Acknowledgements We thank Mr. Philip Ball (University of Cambridge) for providing us with the schematic drawings that are used in this paper. Also, thanks to the photography department at Addenbrooke's Hospital for taking and processing the photos taken intraoperatively.

Compliance with ethical standards This article does not contain any studies with human participants or animals performed by any of the authors.

Conflict of interest The authors declare that they have no conflict of interest.

Open Access This article is licensed under a Creative Commons Attribution 4.0 International License, which permits use, sharing, adaptation, distribution and reproduction in any medium or format, as long as you give appropriate credit to the original author(s) and the source, provide a link to the Creative Commons licence, and indicate if changes were made. The images or other third party material in this article are included in the article's Creative Commons licence, unless indicated otherwise in a credit line to the material. If material is not included in the article's Creative Commons licence and your intended use is not permitted by statutory regulation or exceeds the permitted use, you will need to obtain permission directly from the copyright holder. To view a copy of this licence, visit http://creativecommons.org/licenses/by/4.0/.

\section{References}

1. Gonin J (1935) Le décollement de la rétine: pathogénie, traitement. Arch Ophthalmol 14(1):172-174

2. Wolfensberger TJ, Gonin J (2003) Pioneer of retinal detachment surgery. Indian J Ophthalmol 51(4):303

3. Rumpf J, Gonin J (1976) Inventor of the surgical treatment for retinal detachment. Surv Ophthalmol 21(3):276-284

4. Rice TA, Wilkinson CP, Michels RG (1997) Michels retinal detachment, 2nd edn. Mosby, London, pp 281-303

5. Borley WE (1949) The scleral resection (eyeball-shortening) operation. Trans Am Ophthalmol Soc 47:462-497

6. Lindner KI (1933) Heilungsversuche bei prognostisch ungünstigen Fällen von Netzhautabhebung. Ophthalmologica. 81(5-6):277-299

7. Shapland CD (1961) Developments in detachment surgery during the past thirty years. Trans Ophthalmol Soc Aust 21:19-35

8. Weve H (1949) Bulbusverkürzung durch Reffung der Sclera. Ophthalmologica. 118(4-5):660-665

9. Everett WG (1955) A new scleral shortening operation: preliminary report. AMA Arch Ophthalmol 53(6):865-869

10. Castroviejo R (1956) New clips and clip-applying forceps for scleral shortening procedure. Trans - Am Acad Ophthalmol Otolaryngol Am Acad Ophthalmol Otolaryngol 60(3):483-485

11. Castroviejo R (1960) Retinal detachment surgery: scleral shortening by outfolding with titanium clips. Trans - Am Acad Ophthalmol Otolaryngol Am Acad Ophthalmol Otolaryngol 64: 472-485

12. Chamlin M, Rubner K (1956) Lamellar undermining; a preliminary report on a technique of scleral buckling for retinal detachment. Am J Ophthalmol 41(4):633-638

13. Shipman JS (1958) Retinal detachment surgery: an enfolding of the sclera. AMA Arch Ophthalmol 60(2):247-248

14. Lemoine AN, Robison JT, Calkins LL (1958) A scleral imbrication technique. AMA Arch Ophthalmol 60(2):237-238

15. Swan KC (1959) Scleral imbrication for retinal detachment. AMA Arch Ophthalmol 61(1):110-114
16. Cavka V (1959) Scleral buckling operation with rolled scleral flap. Br J Ophthalmol 43(6):361-365

17. Beasley $H$ (1962) Lamellar infolding of the sclera in retinal detachment. Am J Ophthalmol 54:1031-1033

18. Scheie HG, Jerome B (1949) Electrocoagulation of the sclera: reduction in ocular volume and pathologic changes produced. Am J Ophthalmol 32(6, Part 2):60-78

19. Custodis E (1956) Die Behandlung der Netzhautablosung durch umschriebene Diathermie-koagulation udn einer mittels Plombenaufnahung erzeugtren Eindellung der Sklera im Bereich des Risses. Klin Mbl Augenheilkd 129:476-495

20. Schepens CL, Okamura ID, Brockhurst RJ (1957) The scleral buckling procedures. I. Surgical techniques and management. AMA Arch Ophthalmol 58(6):797-811

21. Schepens CL, Okamura ID, Brockhurst RJ (1958) The scleral buckling procedures: II. Technical difficulties of primary operations. AMA Arch Ophthalmol 60(1):84-92

22. Brockhurst RJ, Schepens CL, Okamura ID (1958) The scleral buckling procedures. III. Technical difficulties of reoperations. AMA Arch Ophthalmol 60(6):1003-1012

23. Okamura ID, Schepens CL, Brockhurst RJ (1959) The scleral buckling procedures. IV. Reoperations following scleral bucklings. Arch Ophthalmol Chic Ill 1960 62:445-458

24. Schepens CL, Okamura ID, Brockhurst RJ, Regan CD (1960) Scleral buckling procedures. V. Synthetic sutures and silicone implants. Arch Ophthalmol Chic Ill 1960 64:868-881

25. Schepens CL (1947) A new ophthalmoscope demonstration. Trans - Am Acad Ophthalmol Otolaryngol Am Acad Ophthalmol Otolaryngol 51:298-301

26. Schepens CL (1951) Progress in detachment surgery. Trans - Am Acad Ophthalmol Otolaryngol Am Acad Ophthalmol Otolaryngol 55:607-615

27. Lincoff H, Gieser R (1971) Finding the retinal hole. Arch Ophthalmol 85(5):565-569

28. Kreissig I, Simader E, Fahle M, Lincoff H (1995) Visual acuity after segmental buckling and non-drainage: a 15-year follow-up. Eur J Ophthalmol 5(4):240-246

29. Lincoff H, Kreissig I (1972) The treatment of retinal detachment without drainage of subretinal fluid. (Modifications of the Custodis procedure. VI). Trans - Am Acad Ophthalmol Otolaryngol Am Acad Ophthalmol Otolaryngol 76(5):1121-1133

30. Lincoff H, Ramirez V, Kreissig I, Baronberg N, Kaufman D (1975) Encircling operations without drainage of subretinal fluid. Mod Probl Ophthalmol 15:188-196

31. Lincoff H, Kreissig I, Uram D (2009) Minor surgery for the repair of retinal detachment emanating from retinoschisis. Acta Ophthalmol 87(3):281-284

32. Lincoff H, McLean JM (1967) Modifications to the Custodis procedure. Am J Ophthalmol 64(5):877-879

33. Lincoff H, McLean JM (1967) Modifications to the Custodis procedure. II. A new silicone implant for large tears. Am J Ophthalmol 64(5):877-879

34. Kreissig I, Lincoff H (1975) Mechanism of retinal attachment after cryosurgery. Trans Ophthalmol Soc U K 95(1):148-157

35. Lincoff HA, Nano H (1965) A new needle for scleral surgery. Am J Ophthalmol 60:146-148

36. Schwartz SG, Kuhl DP, McPherson AR, Holz ER, Mieler WF (2002) Twenty-year follow-up for scleral buckling. Arch Ophthalmol 120(3):325-329

37. Törnquist R, Törnquist P (1988) Retinal detachment. Acta Ophthalmol 66(6):630-636

38. Kreissig I, Rose D, Jost B (1992) Minimized surgery for retinal detachments with segmental buckling and nondrainage. An 11year follow-up. Retina Phila Pa 12(3):224-231 
39. Ung T, Comer MB, Ang AJS, Sheard R, Lee C, Poulson AV et al (2005) Clinical features and surgical management of retinal detachment secondary to round retinal holes. Eye. 19(6):665-669

40. Machemer R (1976) Pars plana vitrectomy. Summary. Trans Sect Ophthalmol Am Acad Ophthalmol Otolaryngol 81(3 Pt 1):431

41. Machemer R, Buettner H, Norton EW, Parel JM (1971) Vitrectomy: a pars plana approach. Trans - Am Acad Ophthalmol Otolaryngol Am Acad Ophthalmol Otolaryngol 75(4):813-820

42. McLeod D (2004) Is it time to call time on the scleral buckle? Br J Ophthalmol 88(11):1357-1359

43. Minihan M, Tanner V, Williamson TH (2001) Primary rhegmatogenous retinal detachment: 20 years of change. $\mathrm{Br} \mathbf{J}$ Ophthalmol 85(5):546-548

44. Miki D, Hida T, Hotta K, Shinoda K, Hirakata A (2001) Comparison of scleral buckling and vitrectomy for retinal detachment resulting from flap tears in superior quadrants. Jpn J Ophthalmol 45(2):187-191

45. SPR Study Group (2003) View 2: the case for primary vitrectomy. Br J Ophthalmol 87(6):784-787

46. Kinori M, Moisseiev E, Shoshany N, Fabian ID, Skaat A, Barak A et al (2011) Comparison of pars plana vitrectomy with and without scleral buckle for the repair of primary rhegmatogenous retinal detachment. Am J Ophthalmol 152(2):291-297.e2

47. Leaver PK, Cooling RJ, Feretis EB, Lean JS, McLeod D (1984) Vitrectomy and fluid/silicone-oil exchange for giant retinal tears: results at six months. Br J Ophthalmol 68(6):432-438

48. Tanner V, Minihan M, Williamson TH (2001) Management of inferior retinal breaks during pars plana vitrectomy for retinal detachment. Br J Ophthalmol 85(4):480-482

49. Ah-Fat FG, Sharma MC, Majid MA, McGalliard JN, Wong D (1999) Trends in vitreoretinal surgery at a tertiary referral centre: 1987 to 1996. Br J Ophthalmol 83(4):396-398

50. Le JR, Behar-Cohen F, Azan F, Bertin S, Bettembourg O, Rumen $F$ et al (2002) Vitrectomy without scleral buckle versus ab-externo approach for pseudophakic retinal detachment: comparative retrospective study. J Fr Ophtalmol 25(3):240-245

51. Campo RV, Sipperley JO, Sneed SR, Park DW, Dugel PU, Jacobsen J et al (1999) Pars plana vitrectomy without scleral buckle for pseudophakic retinal detachments. Ophthalmology. 106(9):1811-1816

52. Barrie T, Kreissig I, Heimann H, Holz ER, Mieler WF (2003) Repair of a primary rhegmatogenous retinal detachment. Br J Ophthalmol 87(6):782-784

53. Snead MP (2016) Retinal detachment in childhood. In: Hoyt CS, Taylor D (eds) Paediatric ophthalmology and strabismus, 5th edn. Elsevier Saunders, London, pp 530-542

54. Heimann H, Bartz-Schmidt KU, Bornfeld N, Weiss C, Hilgers RD, Foerster MH (2007) Scleral buckling versus primary vitrectomy in rhegmatogenous retinal detachment: a prospective randomized multicenter clinical study. Ophthalmology 114(12):21422154.e4

55. Brazitikos PD, Androudi S, Christen WGS, Stangos NT (2005) Primary pars plana vitrectomy versus scleral buckle surgery for the treatment of pseudophakic retinal detachment: a randomized clinical trial. Retina 25(8):957-964

56. Sharma YR, Karunanithi S, Azad RV, Vohra R, Pal N, Singh DV et al (2005) Functional and anatomic outcome of scleral buckling versus primary vitrectomy in pseudophakic retinal detachment. Acta Ophthalmol Scand 83(3):293-297

57. Schaal S, Sherman MP, Barr CC, Kaplan HJ (2011) Primary retinal detachment repair: comparison of 1-year outcomes of four surgical techniques. Retina Phila Pa 31(8):1500-1504

58. Sun Q, Sun T, Xu Y, Yang X-L, Xu X, Wang B-S et al (2012) Primary vitrectomy versus scleral buckling for the treatment of rhegmatogenous retinal detachment: a meta-analysis of randomized controlled clinical trials. Curr Eye Res 37(6):492-499

59. Adelman RA, Parnes AJ, Ducournau D (2013) Strategy for the management of uncomplicated retinal detachments: the European Vitreo-Retinal Society Retinal Detachment Study report 1. Ophthalmology. 120(9):1804-1808

60. Banaee T, Hosseini SM, Ghooshkhanei H, Moosavi M, Khayyatzadeh-Kakhki S (2009) Anatomical and visual outcomes of three different scleral buckling techniques. J Ophthalmic Vis Res 4(2):90-96

61. Kobashi H, Takano M, Yanagita T, Shiratani T, Wang G, Hoshi K et al (2014) Scleral buckling and pars plana vitrectomy for rhegmatogenous retinal detachment: an analysis of 542 eyes. Curr Eye Res 39(2):204-211

62. Velez-Montoya R, Jacobo-Oceguera P, Flores-Preciado J, DalmaWeiszhausz J, Guerrero-Naranjo J, Salcedo-Villanueva G et al (2016) Primary repair of moderate severity rhegmatogenous retinal detachment: a critical decision-making algorithm. Med Hypothesis Discov Innov Ophthalmol J 5(1):18-31

63. Ryan EH, Mittra RA (2010) Scleral buckling vs vitrectomy: the continued role for scleral buckling in the vitrectomy era. Arch Ophthalmol 128(9):1202-1205

64. Tillery WV, Lucier AC (1976) Round atrophic holes in lattice degeneration - an important cause of phakic retinal detachment. Trans Sect Ophthalmol Am Acad Ophthalmol Otolaryngol 81(3 Pt 1):509-518

65. Lincoff H, Kreissig I (1996) Extraocular repeat surgery of retinal detachment: a minimal approach. Ophthalmology. 103(10):15861592

66. Häring G, Wiechens B (1998) Long-term results after scleral buckling surgery in uncomplicated juvenile retinal detachment without proliferative vitreoretinopathy. Retina Phila $\mathrm{Pa}$ 18(6): 501-505

67. Uemura A, Nakao K (1995) A comparison between scleral buckling procedure and vitrectomy for the management of uncomplicated retinal detachment caused by posterior retinal break. Nippon Ganka Gakkai Zasshi 99(10):1170-1174

68. Goto T, Nakagomi T, Iijima H (2013) A comparison of the anatomic successes of primary vitrectomy for rhegmatogenous retinal detachment with superior and inferior breaks. Acta Ophthalmol 91(6):552-556

69. Wickham L, Connor M, Aylward GW (2004) Vitrectomy and gas for inferior break retinal detachments: are the results comparable to vitrectomy, gas, and scleral buckle? Br J Ophthalmol 88(11): 1376-1379

70. Sharma A, Grigoropoulos V, Williamson TH (2004) Management of primary rhegmatogenous retinal detachment with inferior breaks. Br J Ophthalmol 88(11):1372-1375

71. Martínez-Castillo V, Boixadera A, Verdugo A, García-Arumí J (2005) Pars plana vitrectomy alone for the management of inferior breaks in pseudophakic retinal detachment without facedown position. Ophthalmology. 112(7):1222-1226

72. Alexander P, Ang A, Poulson A, Snead M (2008) Scleral buckling combined with vitrectomy for the management of rhegmatogenous retinal detachment associated with inferior retinal breaks. Eye (Lond) 22(2):200-203

73. Afrashi F, Erakgun T, Akkin C, Kaskaloglu M, Mentes J (2004) Conventional buckling surgery or primary vitrectomy with silicone oil tamponade in rhegmatogenous retinal detachment with multiple breaks. Graefes Arch Clin Exp Ophthalmol 242(4):295300

74. Von Fricken MA, Kunjukunju N, Weber C, Ko G (2009) 25Gauge sutureless vitrectomy versus 20-gauge vitrectomy for the repair of primary rhegmatogenous retinal detachment. Retina Phila Pa 29(4):444-450 
75. Scott JD (1998) Basic surgical technique for primary repair of retinal detachment. In: Surgery for retinal and vitreous disease, 1st edn. Butterworth Heinemann, Oxford, pp 47-81

76. Lincoff H, Kreissig I (1994) Finding the retinal hole in the pseudophakic eye with detachment. Am J Ophthalmol 117(4): 442-446

77. Saxena S, Lincoff $H$ (2001) Finding the retinal break in rhegmatogenous retinal detachment. Indian J Ophthalmol 49(3): 199

78. Lincoff H (1976) Radial buckling in the repair of retinal detachment. Int Ophthalmol Clin 16(1):127-134

79. Jackson TL, Donachie PHJ, Sallam A, Sparrow JM, Johnston RL (2014) United Kingdom National Ophthalmology Database study of vitreoretinal surgery: report 3, retinal detachment. Ophthalmology. 121(3):643-648

80. Day S, Grossman DS, Mruthyunjaya P, Sloan FA, Lee PP (2010) One-year outcomes after retinal detachment surgery among Medicare beneficiaries. Am J Ophthalmol 150(3):338-345

81. Mansouri A, Almony A, Shah GK, Blinder KJ, Sharma S (2010) Recurrent retinal detachment: does initial treatment matter? $\mathrm{Br} \mathrm{J}$ Ophthalmol 94(10):1344-1347

82. Wong CW, Wong WL, Yeo IYS, Loh BK, Wong EY, Wong DWK et al (2014) Trends and factors related to outcomes for primary rhegmatogenous retinal detachment surgery in a large Asian tertiary eye center. Retina. 34(4):684-692

83. Chou S-C, Yang C-H, Lee C-H, Yang C-M, Ho T-C, Huang J-S et al (2007) Characteristics of primary rhegmatogenous retinal detachment in Taiwan. Eye. 21(8):1056-1061

84. Alexander P, Prasad R, Ang A, Poulson AV, Scott JD, Snead MP (2007) Prevention and control of proliferative vitreoretinopathy: primary retinal detachment surgery using silicone oil as a planned two-stage procedure in high-risk cases. Eye. 22:815

85. Gonin J (1930) The treatment of detached retina by searing the retinal tears. Arch Ophthalmol 4(5):621-625

86. Gilbert C, McLeod D (1985) D-ACE surgical sequence for selected bullous retinal detachments. Br J Ophthalmol 69(10):733-736

87. Steel DH, West J, Campbell WG (2000) A randomized controlled study of the use of transscleral diode laser and cryotherapy in the management of rhegmatogenous retinal detachment. Retina Phila Pa 20(4):346-357

88. Birchall CH (1979) The fishmouth phenomenon in retinal detachment: old concepts revisited. Br J Ophthalmol 63(7):507-510
89. Smiddy WE, Green WR (1982) Retinal dialysis: pathology and pathogenesis. Retina Phila Pa 2(2):94-116

90. Kennedy CJ, Parker CE, McAllister IL (1997) Retinal detachment caused by retinal dialysis. Aust N Z J Ophthalmol 25(1):25-30

91. Johnston PB (1991) Traumatic retinal detachment. Br J Ophthalmol 75(1):18-21

92. Bonnet M, Moyenin P, Pecoldowa C, Grange JD (1986) Retinal detachment caused by a tear at the ora serrata. J Fr Ophtalmol 9(3): 231-242

93. Ross WH (1981) Traumatic retinal dialyses. Arch Ophthalmol Chic Ill 99(8):1371-1374

94. Stoffelns BM, Richard G (2010) Is buckle surgery still the state of the art for retinal detachments due to retinal dialysis? J Pediatr Ophthalmol Strabismus 47(5):281-287

95. Greven CM, Wall AB, Slusher MM (1999) Anatomic and visual results in asymptomatic clinical rhegmatogenous retinal detachment repaired by scleral buckling. Am J Ophthalmol 128(5): $618-620$

96. Wilkinson CP, Rice TA (1997) Michels retinal detachment, 2nd edn. Mosby, London, pp 678-704

97. Jalkh AE, Avila MP, Schepens CL, Azzolini C, Duncan JE, Trempe CL (1984) Surgical treatments of proliferative vitreoretinopathy. Arch Ophthalmol 102(8):1135-1139

98. Scott JD (1998) Proliferatve vitreoretinopathy. In: Surgery for retinal and vitreous disease. Butterworth Heinemann, Oxford, p 255

99. Williams GA, Aarberg TM (2006) Techniques of scleral buckling. In: Ryan SJ (ed) Retina, 4th edn. Mosby, Edinburgh

100. Chignell AH, Wong D (1999) Management of vitreo-retinal disease. A surgical approach. Springer, London

101. Hendrikse F, Goezinne F, La Heij EC, Liem AT, Bauer N, Goezinne F (2010) The occurrence and treatment of diplopia after scleral buckling surgery for rhegmatogenous retinal detachment (rrd). Invest Ophthalmol Vis Sci 51(13):6067

102. Abdullah AS, Jan S, Qureshi MS, Khan MT, Khan MD (2010) Complications of conventional scleral buckling occuring during and after treatment of rhegmatogenous retinal detachment. J Coll Physicians Surg Pak 20(5):321-326

Publisher's note Springer Nature remains neutral with regard to jurisdictional claims in published maps and institutional affiliations. 